\title{
Research and Analysis of Damping Control Technology in Civil Engineering Construction Process
}

\author{
Yonggang Bao ${ }^{1, *}$, Qingwei Meng ${ }^{1}$ and Ki Bae $\mathrm{Seo}^{2}$ \\ ${ }^{1}$ Henan Vocational College of Water Conservancy and Environment, Zhenzhou 450008, China; ${ }^{2}$ ICT Convergence and \\ Integration Research Division, Korea Institute of Construction Technology, Goyang-Si 412-791, Korea
}

\begin{abstract}
With the rapid development of society and the economy, people's life and property safety importance is also more and more high. Especially the occurrence of the Wenchuan earthquake, people on whether the application of civil engineering construction damping scientific and rational approach was questioned. How to ensure the quality of civil engineering construction, to avoid in the event of earthquakes and other natural disasters, the emergence floor crash event, is an issue for all engineering designers and builders focus on. Because of the relationship with all life safety, so how to use rational scientific method damping to the construction of civil engineering structures is very important and necessary. This study from the passive control, active control, semi-active control and hybrid control methods start with four damping research and analysis, combining their research status. The Benchmark problem of structure control has carried on the simple introduction. Focusing on civil engineering structure vibration control method of systematic review, so as to the future of civil engineering structure suspension construction provides the certain reference function.
\end{abstract}

Keywords: Civil engineering, control, damping, role.

\section{INTRODUCTION}

Mention earthquake, everyone is talking crazy. Because the damage is very large, and it has the characteristics of randomness and sudden, could not accurately predict in advance, so the loss is often caused by very large. In the process of design and construction of civil engineering, the traditional method is to increase the strength and deformation to damping force structure. This method can indeed play a role. The opposite of the traditional methods are nowadays more damping control method advocated, which are obtained by taking isolation, energy consumption, external force, reduce the impact caused by the earthquake. It can greatly adjust the dynamic characteristics and other methods to improve the safety performance, but also has its economic, convenient, scientific and effective characteristics. It is widely used [1]. Theory of civil engineering structures controlled by the Chinese-American scholar Yao Zhiping, which pointed out that the so-called structural control is carried out by the site of a special control, in order to reduce the influence of vibration force to achieve safety and comfort the purpose [2]. According to whether the role of external forces have can be divided into structural vibration control (as shown in Fig. (1)):

\section{PASSIVE CONTROL}

External energy is not being involved in the passive control, because it is itself one of passive acceptance. The use of special devices that have their own sound and shock force of abatement, because of its simple and economic advantages, has been widely attention and application [3]. Divide them from the type, mainly (as shown in Fig. (2)):

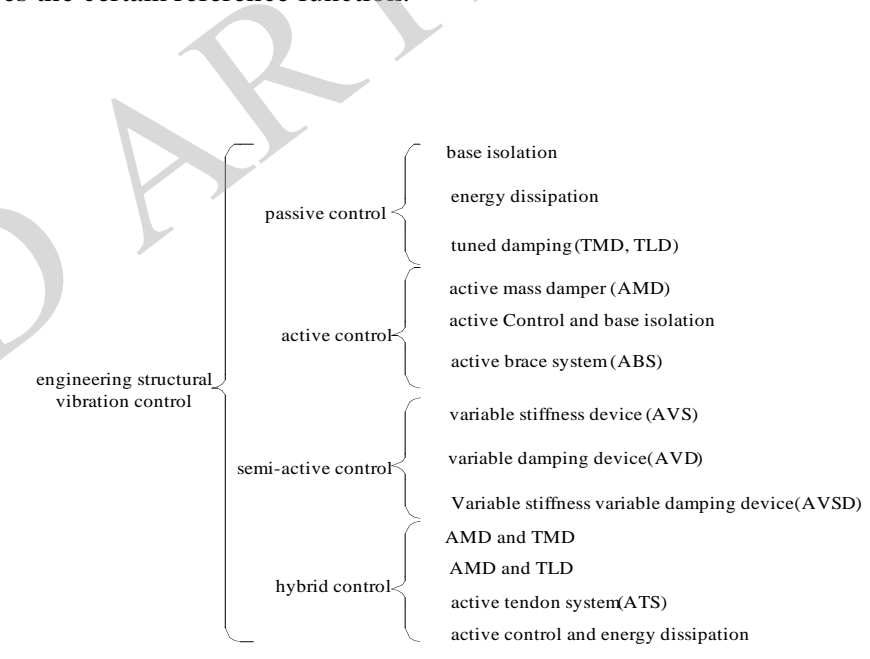

Fig. (1). Structure vibration control division.

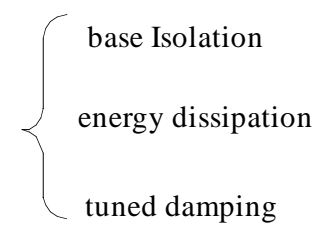

Fig. (2). Type division of passive control.

\subsection{Base Isolation}

The so-called base isolation is to reduce the vibration control mechanism by setting specific damage to the main building. The main isolation devices setting are mezzanine rubber seismic isolation devices, roller and plate energy dissipation devices, powder cushion isolation devices. While these materials must have stiffness and strength requirements, but also have a certain deformation capacity. The most important is a strong resistance. 
Table 1. Energy dissipation system.

\begin{tabular}{|c|c|c|c|}
\hline \multirow{4}{*}{$\begin{array}{c}\text { Energy Dissipation } \\
\text { System }\end{array}$} & $\begin{array}{c}\text { Energy Component } \\
\text { System }\end{array}$ & energy support & $\begin{array}{c}\text { such as block energy support, circular energy support, K-shaped eccentric } \\
\text { energy support, etc. }\end{array}$ \\
\cline { 2 - 4 } & $\begin{array}{c}\text { Damper energy } \\
\text { Dissipation System }\end{array}$ & energy shear wall & $\begin{array}{c}\text { transverse joint shear wall, vertical joints wall, peripheral joints such as shear } \\
\text { walls and shear dampers }\end{array}$ \\
\cline { 2 - 4 } & friction dampers & plastic dampers & mild steel dampers, lead extrusion dampers memory alloy dampers, etc. \\
\hline
\end{tabular}

All methods of base isolation method is applied first, and most widely used, so its technology is relatively mature on the specific operational. But because it has the characteristic of economic, simple, obvious effect, which have become all the most advanced control structures and methods perfect. Japan and other developed countries as early as the eighties of the last century began to gradually increase the base isolated building, particularly the United States and New Zealand and other countries. They built too isolated buildings that it has been a social baptism, truly representative of the majority of the people's voice.

Base isolation technology has matured because of its development, it also has applications in other industries. For example shock protection on the bridge structure is taken to base isolation technology content. Whether it is building or bridge, in the use of base isolation technique is completely on the same. The only difference is the isolation of the area. The bridge is between the pier and beam, while the building is set at the bottom. Worldwide, the first use of base isolation is New Zealand. In the construction of the Motu bridge used U-shaped steel beams bent isolation system. United States and Japan are isolated bridge construction in the 1980s and 1990s. Isolation material is generally lead rubber bearing, stiffness to meet the requirements, but also has good resilience, along with the economy, durability and other characteristics, so in full compliance with the bridge base isolation requirements.

\subsection{Energy Dissipation}

The so-called energy dissipation technology is in the process of designing a particular component intensive. It has consumed shock damping effect, when an earthquake can be very good to protect the security and stability of the main structure $[4,5]$. Depending on energy devices can be divided into energy dissipation system (as shown in the Table 1):

Energy dissipation technology to the traditional essence of the design were to learn and develop. It solved the problem of component repair, with a stable economy, which are widely used in new construction. General energy dissipation technology is mainly used in high-rise buildings, if the number of relatively small projects would not choose this technology.

\subsection{Tuned Damping}

Tuned damping technology is the so-called sub-structure by increasing the ways in which the transfer of vibration force, thereby reducing the force of the earthquake hazard. In the new project in broader application is tuned mass dampers and tuned liquid damper. Tuned mass damper which is a mixture consisting of quality, elastic element and a damper consisting of special equipment installed in the main structure in order to reduce or eliminate shock force. The tuned liquid damper is actually a special kind of water containers, which will be fixed in the structure of the body, by shaking the liquid to digestion shock force. In the construction of the bridge, if the span is relatively large. It is susceptible to wind vibration, so the tuned mass damper is widely used in bridge engineering. But on the question of how to set up, there are still difficult, requires that the designer and the builder resolved. The following Fig. (3) shows the tuning damping design:

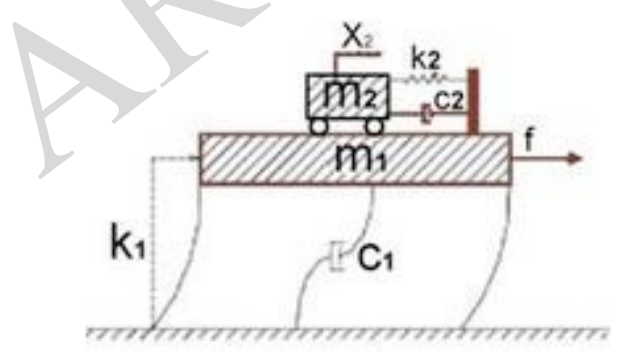

Fig. (3). The tuning damping design.

\section{ACTIVE CONTROL}

Active control and passive control is the corresponding terms, which is to stimulate the internal forces in the structural components of the body, internal forces to digestion by the earthquake force. Active control over the content and function of the system shown as Fig. (4):

Sensor: The sensor response of the measurement structure or external excitation information

Controller. The sensor controller processes the information, the system to achieve the desired rhythm the output of the actuator means

Actuator: generating actuator control the required energy is provided by an external energy source, control sometimes assisted by a substructure is applied to the controlled structure

Fig. (4). Active control over the content and function of the system.

Active control effect does not depend on the control of seismic wave, which is passive control cannot be achieved. Active control system is divided into open-loop control system, closed-loop control system and open-closed-loop control system. Wherein the open-loop control is achieved by measuring the control input data. The closed-loop control 
system is realized by measuring the output of the control data. And the open-closed-loop control system is a combination of the above two systems.

Currently on active control study has two main directions, respectively starting from the algorithms and devices. In the present studies of active control mainly divided into the active control algorithm and the active control device research two parts. In the course of the study requires knowledge structural engineering, computer theory, materials science, mechanical engineering and other disciplines. So that study the structure of the active control is a complex, long-term, multidisciplinary convergence process [5]. From the current research is concerned, in theory, it has made great achievements. But in the actual technical operational level is not very mature, the need to continue their efforts. Research should focus on solving what several constraints:

(1) Operational issues. Many developed countries have AMD and HMD technology to the high-rise buildings, and has achieved good results. It can be well controlled air shock force of the impact and the environment brought about, but in the actual earthquake, it did not play its due effect, and even can be said that does not work.

(2) Delay problem. Control process during the active control, since the calculation, processing and other processes will take time, resulting in the overall running time lag. The situation will seriously affect this lag seismic intensity and time, so be resolved. In the specific remedies, and many experts believe can be achieved by compensating time delay correction method for enhancing the stability of the system and improve control rate.

(3) Energy problems. Active control of the most basic requirement is to have a reliable process control to energy input, energy input excitation through their inner strength. Then how to ensure that at the time of the earthquake to have enough energy input is a need to study and solve problems. (4) Equipment conservation issues. Require the construction projects are relatively long service life. How it can play a role in ensuring the long-term active control of the device, do not lose because of a long time, and this is an all engineering designers and builders should focus on problems.

\section{SEMI-ACTIVE CONTROL}

Semi-active control is to learn the advantages of both active and passive methods, the application of a wider range than the previous two kinds. Semi-active control of the project, the actuator requires only a small amount of force regulate outside, basically does not require external inputs. Generally more common in new construction of semi-active control system has four kinds [7], namely: active tuned mass damper system parameters, variable stiffness systems, variable damping system and variable stiffness variable damping system. Wherein the first control mode is rigid and reaction speed by changing the system to start, to avoid resonance role in achieving the main structure of the seismic effect. Semi-active control mainly through enhanced stiffness, but because the project itself sufficient rigidity, so the use of semi-rigidity of the system development is limited, just change the corresponding semi-active control system developed. The third method is to control the damping force control device improved. The input force is the same principle, in order to achieve enhanced damping effect, and even active control comparable. Semi-active variable damping control device is to solve the problem with the speed, of course the speed of the finest in the displacement and active control or cannot be compared, but the advantage is with the stability. And on the basis of active control theory, it can determine in advance the intensity and effectiveness of controls. Thus damping value is set to best control and effect. Semi-active control method draws on the advantages of active and passive two ways. Control structures and structural response from both the outside world, this process does not require a special external forms, the ability to provide long battery can operate. Semi-active control because it has the advantages of both active and passive, both economical and reliable features, but does not require special maintenance. So it is a new project. The most widely used method of damping control. First proposed semi-automatic control theory is Hrovat, which considers semi-active control system to achieve optimal control of the state. Kobori and others based on results of previous studies, proposed the concept of rigid control and algorithms. In the same year in Japan, semi-active control system for the first time to the rigid application, which is used in a three-story building structure, after the actual application, the effect is very obvious. In contrast, the semi-active control study in China started late, until 1990 by Wang Bi and Li Minxia and other personnel to become just the theory of semi-active research and use. In 2003 the process of building Shandong Binzhou Yellow River Bridge in Lee Hui and Ou Jinping, who will eventually be applied to the magneto-rheological dampers actual construction projects.

\section{HYBRID CONTROL}

Hybrid control concept will be understood from the literal meaning, that is the active and passive methods of controlling simultaneously performed on a structure. Their combination and proportion of different ways is resulting structural damping different forms. Generally it divided into combinations and two types of parallel manners. Combination is to set a main control unit, the remaining parts of the control work should focus on the main control components, but not from their work. Parallel manner by two main control unit, there is a parallel relationship between the two. It does not interfere with each other. For now, in recent years, more and more research and refinement is mainly passive, active, supplemented by a combination of methods. The Fig. (5) below shows the hybrid control in civil engineering construction design:

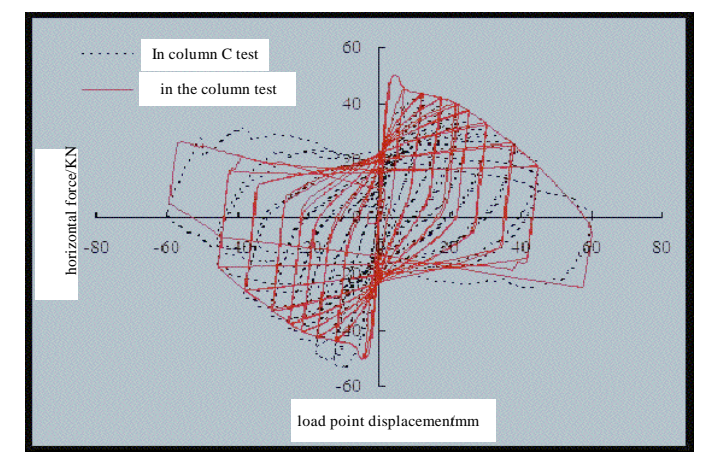

Fig. (5). He hybrid control in civil engineering construction design. 
Hybrid control is mainly active control and passive control connected. After connecting their advantages can be well forward, while overcoming their disadvantages. This would not only be able to achieve the introduction of active control, increasing the scope and effectiveness of the regulation, but also because in the process of active control, more or less passive control of ingredients added. So it can effectively reduce the required control, enhance seismic effects and stability $[6,7]$.

\section{BENCHMARK ISSUE OF CIVIL ENGINEERING STRUCTURAL VIBRATION CONTROL}

Civil engineering in the construction process, how to achieve good vibration control effect, depending on a variety of related factors than their own can solve. Factors include: the external environment, characterized by the structure itself, the type of control apparatus, the control method of the calculation, the observed variables. Facing so many factors influence how to establish a specific pattern or indicators such indicators or patterns can be unified measure various factors, and development proposed Benchmark problem is this problem solved.

Benchmark means that in theory consistent with the structure and the environment and other external conditions, established a comprehensive system designed for structural vibration control testing and evaluation. It realized providing a common platform for various control schemes ratio. Question refers to the same structural model, environmental interference and performance indicators, to establish a comprehensive inspection and evaluation of structural vibration control system. Thereby it provided a common platform for comparing different control schemes. Benchmark theory was proposed in 1994, after nearly 20 years of development, it has spent three stages: the first stage of development is mainly used two three-story building as the object of the experiment, each of them to take the initiative to pull cable quality control and active drive control, analyze how effectively controlled scientific computing in the case of an earthquake. The second development of as example of two highrise buildings, respectively on the seismic and wind resistance design, analysis, in this case how to develop the scientific and reasonable control scheme. The third development stage into the research and application of Benchmark theory, the development of this theory will be the most recent main developments. Jung et al believe that through the use of large-scale magnetorheological dampers, combined with the optimal control algorithm can be applied to the semi-active control bridges Benchmark model. Agrawal conducted a variety of control methods of science than right, eventually raised its Benchmark model applied to the bridge being to improve the seismic response control effect.

\section{CONCLUSION}

In summary, from a development perspective to look at civil engineering structural vibration control technology, base isolation and shock absorption due to the research and application of energy consumption are early, so now the technology is mature, and a very wide range of applications. In after continuing to strengthen the regulation and management, keep its practicability and stability. The effect of passive damping control devices have a great relationship, so its damping effect has uncertainty. Compared with passive control, active control results significantly better, although it has also made great achievements in the relevant theoretical research. But because it is still not mature in the application of technology, but also by the energy, maintenance and operating costs affected. Semi-active control technology is a combination of active and passive premise two control methods, with all the advantages of both. It is more economical and effective, and is the future of the main research goals. The reasons of wide range for hybrid control application, is mainly because of its application flexibility, especially with the isolation and its energy dissipation characteristics. In the future, the construction of civil engineering structures, the choice of damping control method based on scientific and reasonable to protect the quality of the project, for social and economic development has played the role of escort.

\section{CONFLICT OF INTEREST}

The authors confirm that this article content has no conflict of interest.

\section{ACKNOWLEDGEMENTS}

Fund Project: Henan Provincial Department of education in 2014, the focus of the project, the fund number: ZJA14118.

\section{REFERENCES}

[1] L. C. Fan and Z. Q. Wang, Bridge Seismic Isolation Design. Beijing: People's Communications Press, 2000.

[2] G. Peng and G. D. Zhang, Civil Engineering Structural Vibration Control. Wuhan: Wuhan University of Technology Press, 2002, pp. $1-152$.

[3] J. Cai, Seismic Response of Long Span Cable-stayed Active Control Study. Chengdu: Southwest Jiaotong University, 2001.

[4] Q. H. Yu, The theoretical and Experimental Study of Passive Control of the Bridge Structure. Shanghai: Tongji University, 2001.

[5] Y. C. Jiang, Structural Base Isolation Reverse Reaction. Wuhan: Huazhong University of Science and Technology, 2001.

[6] K. M. Pan, Damping Rubber Pad Sets Situ Testing and Dynamic Response Analysis. Shenyang: Northeastern University, 2002.

[7] S. F. Zhao, Research and Application of Laminated Rubber Base Isolation Structure. Nanjing: Southeast University, 2001. 